\title{
Propriedades Antioxidantes e antimicrobianas de filmes de amido contendo extrato de própolis
}

\author{
S. J. de SOUZA ${ }^{1}$, M. V. da SILVA ${ }^{1}$, F. V. LEIMANN ${ }^{1}$, M. A. SHIRAI ${ }^{1}$ \\ ${ }^{1}$ Universidade Tecnológica Federal do Paraná, Departamento Acadêmico de Alimentos \\ E-mail para contato: silvio.souza93@hotmail.com
}

\begin{abstract}
RESUMO - Este trabalho teve como objetivo produzir filmes de amido de mandioca com diferentes concentrações de extrato etanólico de própolis (EP) $(0$; $0,5 \% ; 0,75 \%$ e $1 \% \mathrm{p} / \mathrm{p}$ ) pela técnica de casting. Nos filmes obtidos foram determinadas as atividades antioxidade e antimicrobiana frente aos microrganismos Escherichia coli e Staplylococcus aureus. Para determinar a atividade antioxidante, inicialmente foi feita a extração dos compostos fenólicos da matriz polimérica com etanol e em seguida foi determinada a quantidade de compostos fenólicos totais e a capacidade antioxidante pelo método DPPH. Pelos resultados obtidos observou-se que foi possível extrair compostos fenólicos contidos nas matrizes poliméricas do filme de amido e notou-se que o processo de fabricação do filme não degradou esses compostos. Os resultados da capacidade antioxidante ainda mostraram que os compostos fenólicos contidos nas matrizes atuaram como antioxidantes. Diferente da formulação controle, os filmes contendo EP apresentaram atividade antimicrobiana frente aos microrganismos testados, devido aos compostos fenólicos presentes no EP. Com este trabalho concluiu-se que o EP possui potencial para ser utilizado como aditivo na produção de embalagens ativas biodegradáveis, pois proporcionou atividade antimicrobiana e antioxidante.
\end{abstract}

\section{INTRODUÇÃO}

Nos últimos anos o número de produtos industrializados tem sido crescente, com isso um dos maiores desafios da indústria de alimentos é a preocupação com os resíduos gerados, onde se destacam as embalagens. Com isso houve um grande aumento em pesquisas sobre filmes biodegradáveis que são produzidos a partir de biopolímeros, como proteínas do soro do leite, proteínas do milho, glúten do trigo, amidos, colágenos, albuminas, celulose, pectina, entre outros (Tharanathan, 2003).

Além disso, tem-se a preocupação com a deterioração dos alimentos, seja ela de ordem microbiológica ou físico-química. Isso tem motivado a pesquisa e desenvolvimento de embalagens ativas, uma vez que estas não só podem atuar como barreira a agentes externos, como também podem apresentar substâncias com atividade funcional como os antioxidantes e antimicrobianos. Assim, a incorporação destes compostos em biopolímeros resultaria em uma embalagem biodegradável ativa e capaz de aumentar a vida de prateleira do produto (Bodini et al., 2013; Chen et al., 2010; Pereira de Abreu et al., 2011). 
Os compostos bioativos, como antioxidantes e antimicrobianos, selecionados para incorporar neste tipo de filme deve ter grau alimentício e ser de preferência de origem natural, uma vez que os compostos sintéticos apresentam efeitos adversos no meio ambiente e podem prejudicar a saúde do consumidor. Existem varias substâncias naturais sendo estudadas como aditivos na produção de filmes biodegradáveis como os óleos essenciais, enzimas, bacteriocinas e ácidos orgânicos. Entre elas uma substância altamente encontrada e que se destaca pelo seu potencial antioxidante, antimicrobiano, anti-inflamatório, antitumoral e anestésica é a própolis. (Bodini et al., 2013; Cagri et al., 2004)

A própolis é uma substância resinosa, coletadas pelas abelhas de exsudações de brotos e botões florais de variados tipos de plantas. Possui coloração e consistência variada, e é utilizada pelas abelhas na colmeia para reparar os favos de mel, embalsamar insetos mortos, reparar frestas e proteger a colmeia contra microrganismos. Sua composição nutricional depende da biodiversidade frequentada pela abelha, portanto as substâncias encontradas na própolis estão relacionadas com a composição química da resina coletada da planta. Os compostos fenólicos, como principal os flavonoides, são considerados um dos principais compostos bioativos da própolis, junto com os derivados do acido cinâmico e seus ésteres (Cabral, 2009).

Vários estudos reportam a aplicação do extrato etanólico de própolis (EP) na produção de filmes a base de gelatina, hidroxipropilmetilcelulose, carragena e amido de milho (Bodini et al., 2013; Chang-Bravo et al., 2014; Pastor et al., 2010). Entretanto, não foram encontrados trabalhos sobre a incorporação de extrato de própolis na formulação de filmes a base de amido de mandioca para uso como embalagens ativas. Desta forma, este trabalho visa produzir filmes de amido de mandioca adicionados de diferentes concentrações de extrato de própolis e avaliar se as condições de processo interferiram na capacidade antioxidante e antimicrobiana dos mesmos.

\section{MATERIAL E MÉTODOS}

\subsection{Material}

Para a produção dos filmes foi utilizado amido de mandioca (Indemil, Paranavaí, Brasil), glicerol (Dinâmica, São Paulo, Brasil) como plastificante e extrato etanólico de própolis (Real Mel, Campo Mourão, Brasil) com 12\% (p/v) de sólidos. Para avaliação da atividade antimicrobiana empregou-se os microrganismos Escherichia coli (IAL339) e Staphylococcus aureus (IAL1875). O reagente Folin-Ciocalteu (Sigma Aldrich, USA), carbonato de sódio (Vetec, Brasil) e ácido gálico padrão (Sigma Aldrich, USA) foram utilizados na determinação da concentração de compostos fenólicos totais dos filmes e DPPH (2,2-diphenyl-picrylhydrazyl, Sigma Aldrich, USA) foi usado para avaliar a atividade antioxidante.

\subsection{Produção dos Filmes}

Os filmes de amido foram produzidos pela técnica de casting de acordo com Mali et al. (2005) com algumas modificações. A concentração de amido foi de $3 \mathrm{~g}$ de amido / $100 \mathrm{~g}$ de solução filmogênica, a de glicerol foi de $20 \mathrm{~g} / 100 \mathrm{~g}$ de amido e foram estudadas três 
concentrações de extrato alcóolico de própolis $(0 ; 0,5 ; 0,75 ;$ e $1 \%)$ em relação à solução filmogênica total.

Todos os componentes foram pesados e misturou-se a água, o glicerol e o amido em um béquer. Essa mistura foi aquecida até $70{ }^{\circ} \mathrm{C}$ (para garantir a gelatinizarão do amido de mandioca) sob agitação manual, em uma chapa aquecedora Solab (Piracicaba - SP, Brasil). Em seguida adicionou-se o EEP e continuou-se a agitação até atingir a temperatura de $80{ }^{\circ} \mathrm{C}$. Essa solução filmogênica foi espalhada em forma revestida de teflon e seca em estufa com circulação de ar (Nova ética, São Paulo, Brasil) a $40^{\circ} \mathrm{C}$ por 16 horas.

\subsection{Atividade Antimicrobiana}

Para esta análise, inicialmente, as bactérias Staphylococcus aureus e Escherichia Coli foram reativadas em caldo Müller-Hinton, a $35^{\circ} \mathrm{C}$, até alcançar ou exceder a turbidez de uma solução padrão de McFarland de 0,5. Placas de ágar Müller-Hinton, previamente preparadas, foram então inoculadas em superfície com 0,1 ml de Staphylococcus aureus e Escherichia Coli $\left(10^{8} \mathrm{UFC} / \mathrm{mL}\right)$ e discos de $2 \mathrm{~mm}$ de diâmetro dos filmes foram colocados sobre a superfície das placas, sendo as mesmas incubadas a $37^{\circ} \mathrm{C}$ por 24 horas. Após este período observou se houver a formação de halos de inibição.

\subsection{Atividade Antioxidante}

Extração dos compostos antioxidantes: Em um tubo cônico de $50 \mathrm{~mL}$ foram adicionados $1 \mathrm{~g}$ de filme e $20 \mathrm{~mL}$ de álcool etílico a $50{ }^{\circ} \mathrm{C}$, e homogeneizou-se por 15 minutos a $6000 \mathrm{rpm}$ em um ultra-turrax (IKA, modelo T25, Brasil), com o sistema mantido em banhomaria a $50{ }^{\circ} \mathrm{C}$. Após a mistura foi centrifugada a $6000 \mathrm{rpm}$ por 15 minutos, o sobrenadante foi coletado, e a extração foi repetida por duas vezes com $40 \mathrm{~mL}$ de álcool etílico. As três frações extraídas foram mantidas a $-20^{\circ} \mathrm{C}$ e analisadas separadamente quanto ao teor de compostos fenólicos totais e à capacidade antioxidante.

Teor de fenólicos totais: O teor de fenólicos totais (FT) nos filmes foi determinado de acordo com o método de Folin-Ciocalteu (Singleton e Rossi, 1995), no qual os ácidos fosfotúngstico e fosfomolíbdico são reduzidos pelos compostos fenólicos a óxidos de tungstênio e de molibdênio, formando uma solução de cor azul de intensidade correspondente à concentração daqueles compostos antioxidantes.

Em um tubo de ensaio foram misturados $30 \mu \mathrm{L}$ de extrato, $2370 \mu \mathrm{L}$ de água destilada e $150 \mu \mathrm{L}$ do reagente de Folin-Ciocalteu. O branco foi preparado com $30 \mu \mathrm{L}$ de etanol, usado como solução extratora. Após 2 minutos, foram acrescentados $450 \mu \mathrm{L}$ de carbonato de sódio a $15 \%(\mathrm{~m} / \mathrm{v})$ e os tubos mantidos em ambiente escuro a temperatura ambiente por 2 horas. Leituras em absorbância foram obtidas a $765 \mathrm{~nm}$ usando um espectrofotômetro UV-VIS (Red Tide, modelo USB650 UV, programa de aquisição de dados SpectraSuit 2.0.162, Ocean Optics, Duneden, EUA). Uma curva padrão de ácido gálico com concentrações entre 30 e $1500 \mathrm{mg} / \mathrm{L}\left(\mathrm{y}=0,0011 \mathrm{x}-0,0088, \mathrm{R}^{2}=0,9995\right)$ foi utilizada para a quantificação dos FT, que foram expressos em miligramas equivalente de ácido gálico por $100 \mathrm{~g}$ de filme (mg EAG/100 g). Os resultados dos três extratos obtidos por filme foram somados para compor o valor final. 
Capacidade antioxidante pelo método de DPPH: A capacidade antioxidante foi avaliada pelo método do radical de DPPH (DPPH ${ }^{\bullet}$ ) de acordo com Mensol et al. (2001), que se baseia na capacidade de um antioxidante reduzir o $\mathrm{DPPH}^{\bullet}$ por uma reação de transferência de elétrons, descorando a solução. O volume de $1000 \mu \mathrm{L}$ de uma solução metanólica de $\mathrm{DPPH}^{\bullet}$ a $0,3 \mathrm{mmol} / \mathrm{L}$ foi misturado a $2500 \mu \mathrm{L}$ de extrato. O controle negativo foi preparado substituindo o extrato por $2500 \mu \mathrm{L}$ de álcool etílico, e um branco para cada extrato foi preparado substituindo a solução de $\mathrm{DPPH}^{\bullet}$ por $1000 \mu \mathrm{L}$ de álcool metílico. Após 30 minutos de incubação a temperatura ambiente em local escuro, foram obtidas leituras em absorbância a $518 \mathrm{~nm}$ usando um espectrofotômetro UV-VIS (Red Tide, modelo USB650 UV, programa de aquisição de dados SpectraSuit 2.0.162, Ocean Optics, Duneden, EUA). Os resultados foram quantificados por uma curva de calibração de trolox com concentrações de 10 a 60 $\mu \mathrm{mol} / \mathrm{L}\left(\mathrm{y}=-0,0168 \mathrm{x}+1,0728, \mathrm{R}^{2}=0,9977\right)$, e expressos em micromol equivalente de trolox por $100 \mathrm{~g}$ de filme $(\mu \mathrm{mol} \mathrm{ET} / 100)$. Os resultados dos três extratos obtidos por filme foram somados para compor o valor final.

\section{RESULTADOS E DISCUSSÕES}

\subsection{Atividade Antioxidante}

Os filmes obtidos apresentaram coloração amarela, devido à coloração do $\mathrm{EP}$, aspectos físicos de fácil manuseabilidade, foram facilmente retirados das formas e foi possível notar também que os filmes contendo EP ficaram menos quebradiços.

Inicialmente foram testadas várias proporções de água e etanol para a extração dos compostos fenólicos, mas verificou-se que isso causou turbidez nos extratos, possivelmente por insolubilização das resinas, ceras e óleos essenciais de sua composição, interferindo negativamente nos ensaios espectrofotométricos. Diante desta situação, optou-se por fazer extração dos compostos fenólicos apenas com etanol. Os resultados de compostos fenólicos totais e capacidade antioxidante dos filmes adicionados de extrato de própolis estão apresentados na Figura 1.

Conforme aumentou-se a concentração de EP, elevou-se a quantidade de compostos fenólicos presentes no filmes e os valores variaram de 326 a $701 \mathrm{mg}$ EAG/100 g de filme. De acordo com a literatura, rutina, quercetina e naringenina são os compostos fenólicos geralmente encontrados em EP (Siripatrawan et al., 2013). Com isso pode-se afirmar que o método de extração com etanol foi eficaz, e que os filmes de amido incorporados com extrato alcoólico de própolis mantiveram em sua matriz polimérica os compostos contidos no extrato e que as condições de processamento do filme foram adequadas.

Ainda de acordo com a Figura 1, a capacidade antioxidante dos filmes foi proporcional à quantidade de EP nos filmes e está diretamente associada com os compostos fenólicos presentes no EP, conforme relatado em outros estudos (Chang-Bravo et al., 2014; Siripatrawan et al., 2013). 
Figura 1 - Compostos fenólicos totais e capacidade antioxidante dos filmes de amido adicionados de EP



\subsection{Atividade Antimicrobiana}

Os resultados da atividade antimicrobiana, expressos em termos de diâmetro do halo de inibição, avaliada a partir do método de disco-difusão estão apresentados na Tabela 1.

Tabela 1 - Diâmetro dos halos (mm) de inibição dos filmes de amido adicionados de EP

\begin{tabular}{ccccc}
\hline & \multicolumn{4}{c}{ Diâmetro da zona de inibição (mm) } \\
\cline { 2 - 5 } Microrganismo & Controle & EP 0,5\% & EP 0,75\% & EP 1\% \\
\hline Escherichia coli & 0 & $7,0 \pm 0,3$ & $9,5 \pm 0,3$ & $10,0 \pm 0,5$ \\
\hline Staphylococcus aureus & 0 & $8,0 \pm 0,1$ & $7,5 \pm 0,1$ & $9,0 \pm 0,3$ \\
\hline
\end{tabular}

Conforme a Tabela 1 pode-se observar que todas as amostras contendo EP apresentaram halos de inibição frente a Staphylococcus aureus e Escherichia coli, que variaram de 7,0 a 9,5 mm. De acordo com Siripatrawan et al. (2013), o extrato de própolis é mais efetivo contra bactérias Gram positivas do que Gram negativas devido à diferença na estrutura da parede celular. Entretanto, neste trabalho não se pode concluir para qual grupo de bactérias o filme foi mais efetivo. Bodini et al. (2013) também verificaram atividade antimicrobiana frente a Staphylococcus aureus em filmes de gelatina adicionados de EP. 


\section{CONCLUSÃO}

Com este trabalho pode-se concluir que os filmes de amido adicionados de EP, mesmo levando em consideração as condições de processamento, ainda mantiveram os compostos fenólicos que foram responsáveis pela atividade antimicrobiana e antioxidante. Desta forma, o EP possui grande potencial para ser utilizado como aditivo na produção de embalagens ativas para alimentos.

\section{REFERÊNCIAS}

Bodini, R. B.; Sobral, P. J. A.; Favaro-Trindade, C. S.; Carvalho, R. A. Properties of gelatinbased films with added ethanol-propolis extract. LWT Food Sci. Technol., v. 51, p.104-110, 2013.

Cabral, I. S. R.; Oldoni, T. L. C.; Prado, A.; Bezerra, R. M. N.; Alencar, S. M. de; Ikegaki, M.; Rosalen, P. L. Composição fenólica, atividade antibacteriana e antioxidante da própolis vermelha brasileira. Quím. Nova, v. 32, p. 1523-1527, 2009.

Cagri, A.; Ustunol, Z.; Ryser, E. T. Antimicrobial edible films and coatings. J. Food Prot., v. 67, p. 833-48, 2004.

Chang-Bravo, L.; López-Córdoba, A.; Martino, M. Biopolymeric matrices made of carrageenan and corn starch for the antioxidant extracts delivery of Cuban red propolis and yerba mate. React. Funct. Polym., v. 85, p. 11-19, 2014.

Chen, C.-P.; Wang, B.-J.; Weng, Y.-M. Physiochemical and antimicrobial properties of edible aloe/gelatin composite films. Int. J. Food Sci. Technol., v. 45, p. 1050-1055, 2010.

Mensor, L. L.; Menezes, F. S.; Leitão, G. G.; Reis, A. S.; Santos, T. C. de; Coube, C. S.; Leitão, S. G. Screening of Brazilian plant extracts for antioxidant activity by the use of DPPH free radical method. Phytother. Res., v. 15, p. 127-130, 2001.

Pastor, C.; Sánchez-González, L.; Cháfer, M.; Chiralt, A.; González-Martínez, C. Physical and antifungal properties of hydroxypropylmethylcellulose based films containing propolis as affected by moisture content. Carbohydr. Polym., v. 82, p. 1174-1183, 2010.

Pereira de Abreu, D. A.; Cruz, J. M.; Paseiro Losada, P. Active and Intelligent Packaging for the Food Industry. Food Rev. Int., v. 28, p. 146-187, 2001.

Singleton, V. L.; Rossi, J. A. Colorimetry of Total Phenolics with PhosphomolybdicPhosphotungstic Acid Reagents. Am. J. Enol. Vitic., v. 16, p. 144-158, 1965.

Siripatrawan, U.; Vitchayakitti, W.; Sanguandeekul, R. Antioxidant and antimicrobial properties of Thai propolis extracted using ethanol aqueous solution. Int. J. Food Sci. Technol., v. 48, 22-27, 2013.

Tharanathan, R. N. Biodegradable films and composite coatings: past, present and future. Trends Food Sci. Technol., v. 14, p. 71-78, 2003. 